MoRrIs, E. J. (1958). J. gen. Microbiol. 19, 305-311

\title{
Selective Media for some Pasteurella Species
}

\author{
By E. J. MORRIS \\ Microbiological Research Establishment, Ministry of Supply, \\ Porton, Wiltshire
}

SUMMARY: Three selective media are described for the isolation of Pasteurella pestis, $P$. septica, $P$. pseudotuberculosis and $P$. haemolytica from material heavily contaminated with other bacteria.

During studies carried out in this establishment on organisms of the genus Pasteurella, media were often required that would assist in the isolation of these organisms from material heavily contaminated with other bacteria. Selective media for this purpose previously reported by Drennan \& Teague (1917), Meyer \& Batchelder (1926) and Thal \& Chen (1955) were found to allow the growth of many Gram-negative bacteria and were only of limited use. Recent screening tests on a large number of substances revealed the potential value of Novobiocin and Neomycin for the selective growth of certain Pasteurella spp. This report is concerned with the formulation of media using these substances for the detection of $\boldsymbol{P}$. pestis, $\boldsymbol{P}$. septica, $\boldsymbol{P}$. pseudotuberculosis and $P$. haemolytica.

\section{METHODS}

Basal media. It was shown by Herbert (1949) that the aerobic growth of Pasteurella pestis on nutrient agar would occur quantitatively only when haemin, blood, or a reducing substance such as sodium sulphite, was added to the agar medium. The growth of pasteurellas was therefore compared, in the presence of selective substances, on peptone agar, tryptic digest of beef agar (TMA) and Difco tryptose agar (TA) with the addition of Fildes's (1920) digest of sheep's blood (PSB), sodium sulphite, or haemin. PSB was not necessary for the growth of some species but allowed the quantitative growth of all pasteurellas in higher concentrations of the selective agents than did haemin. Sodium sulphite in some instances diminished the selectivity of the media.

The growth of pasteurellas was better on TMA and TA than on peptone agar. Colonies of Pasteurella pestis and P. haemolytica were larger on TA but TMA produced the largest colonies of $P$. septica. P. pseudotuberculosis grew equally as well on TMA or TA. Within the range $\mathrm{pH} 6 \cdot 8-7 \cdot 8$ the $\mathrm{pH}$ value of the medium had little effect on growth.

The basal media finally adopted were TMA for Pasteurella septica and $\boldsymbol{P}$. pseudotuberculosis, and TA for $\boldsymbol{P}$. pestis and $\boldsymbol{P}$. haemolytica both at $\mathrm{pH} \mathbf{7 \cdot 6}$ sterilized in $8 \mathrm{oz}$. bottles at $120^{\circ}$ for $20 \mathrm{~min}$. The addition of $5 \%(\mathrm{v} / \mathrm{v})$ peptic sheep's blood and of solutions of the selective agents in sterile distilled water, was made to the melted agar cooled to $50^{\circ}$. Petri dishes filled with $20 \mathrm{ml}$. amounts of the media were dried with the lids removed for $2 \mathrm{hr}$. at $37^{\circ}$ to 
remove surface moisture; they could be stored at $4^{\circ}$ for at least 7 days without loss in selective properties.

Growth tests. The Miles \& Misra (1938) technique was used to inoculate the basal and test media with pure cultures of pasteurellas and common contaminant organisms. In one series of experiments (Table 2) media were inoculated by a less accurate method. One drop of each pasteurella suspension was streaked radially on the medium with a Pasteur pipette, 10 strains being inoculated on each agar plate. The suspensions were diluted to give $c .100$ colonies/drop. The number of colonies subsequently grown on the test media was estimated and compared with that obtained on the basal nutrient agar. Samples of the Pasteurella spp. were also added to suspensions in water, of soil $(1 \mathrm{~g} . / 20 \mathrm{ml}$.), faeces $(1 \mathrm{~g} . / 100 \mathrm{ml}$.) and straw $(5 \mathrm{~g} . / 30 \mathrm{ml}$.) so that $0.1 \mathrm{ml}$. when plated on the media would yield $c .200$ pasteurella colonies. Incubation was at $37^{\circ}$ for $48 \mathrm{hr}$. for all species; $P$. pestis was also grown at $30^{\circ}$.

\section{RESULTS}

Growth of pure cultures. Selective substances were added individually to both basal media and tested with pure cultures of pasteurellas and contaminant organisms. There were marked differences in sensitivity to the selective agents among the Pasteurella spp. At concentrations showing some selective action, Novobiocin inhibited the growth of $P$. septica, partially inhibited $\boldsymbol{P}$. haemolytica but allowed quantitative growth of $\boldsymbol{P}$. pestis and $\boldsymbol{P}$. pseudotuberculosis. Neomycin inhibited $P$. pseudotuberculosis, partially inhibited $\boldsymbol{P}$. pestis but allowed normal growth of $\boldsymbol{P}$. septica and $\boldsymbol{P}$. haemolytica. Differences in sensitivity to potassium tellurite, Erythrocin and Tyrothricin were also found. The colony counts from some strains of each species were lowered in the presence of selective agents, but it was possible to adjust final concentrations in the media to a value which allowed normal growth of the maximum number of strains. $P$. pestis required an incubation temperature of $30^{\circ}$, higher temperatures resulted in irregularly sized colonies and smaller counts; $37^{\circ}$ was preferred for growth of the other species. Colonies of pasteurellas were slightly smaller on the test media than on basal agar but were otherwise typical in appearance.

The selectivity obtained from individual additions to the media was inadequate for detection of pasteurellas from heavily contaminated material. Novobiocin allowed the growth of some Gram-negative bacteria, although it partially inhibited Proteus vulgaris and controlled its swarming. Neomycin effectively inhibited growth from Gram-negative contaminant organisms, including $\boldsymbol{P}$. vulgaris, but did not affect Streptococcus faecalis or Micrococcus spp. The results are summarized in Table 1.

Certain mixtures of the selective substances were added to TMA and TA basal nutrient agar containing $5 \%$ PSB, and tested with pure cultures of Pasteurella spp. The results from a typical experiment are shown in Table 2. Medium 1, containing Novobiocin $10 \mu \mathrm{g} . / \mathrm{ml}$. + potassium tellurite $5 \mu \mathrm{g} . / \mathrm{ml} .+$ Erythrocin $5 \mu \mathrm{g} . / \mathrm{ml}$. gave quantitative growth of $\boldsymbol{P}$. pestis and $\boldsymbol{P}$. pseudotuberculosis while inhibiting $\boldsymbol{P}$. septica and $\boldsymbol{P}$. haemolytica. Colonies of each 
Table 1. Growth of pasteurellas and contaminant organisms on basal nutrient agar containing $5 \%$ PSB with added selective agents

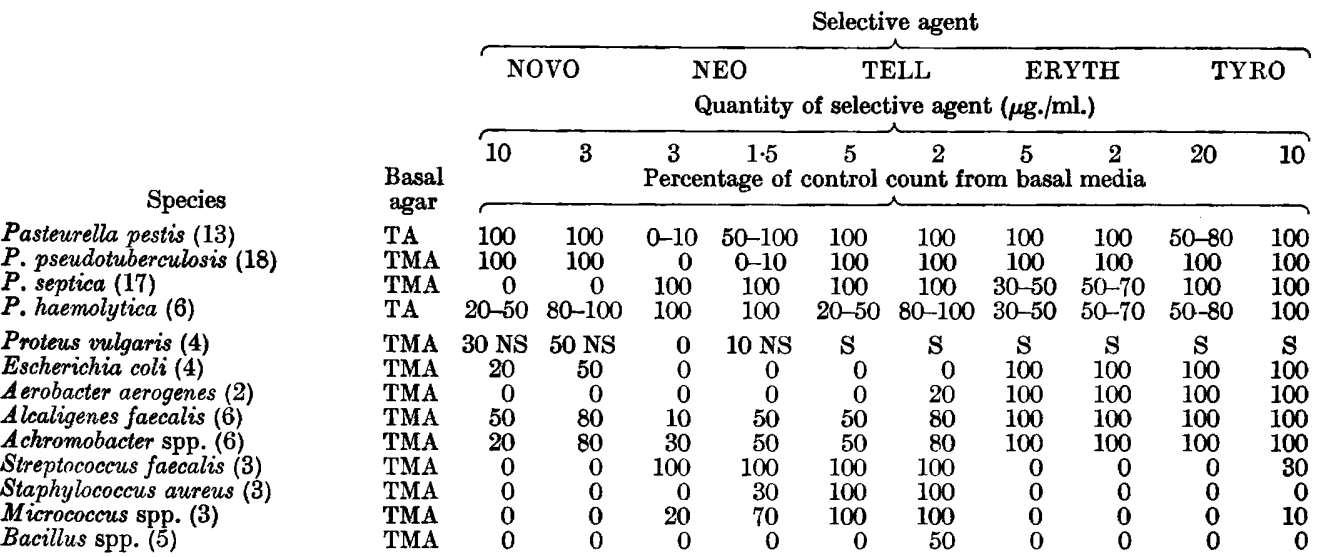

Figures in parentheses refer to the number of strains tested. $\mathrm{NS}=$ not swarming; $\mathrm{S}=\mathrm{swarming}$; NOVO=Novobiocin; $\mathrm{NEO}=$ Neomycin; TELL= potassium tellurite; ERYTH=Erythrocin; TYRO=Tyrothricin.

species grown were $c .1 \cdot 2 \mathrm{~mm}$. in diameter after $48 \mathrm{hr}$. of incubation and were of typical appearance.

The majority of strains of Pasteurella septica and two strains of $\boldsymbol{P}$. haemolytica grew normally on medium 3 which contained: Neomycin $2.5 \mu \mathrm{g} . / \mathrm{ml} .+$ Tyrothricin $10 \mu \mathrm{g} . / \mathrm{ml}$. P. pestis was partially inhibited on this medium and $P$. pseudotuberculosis completely suppressed. With potassium tellurite added to medium 3 (Table 2) the growth of $P$. septica only was obtained; colony counts from 5 of 17 strains, however, were then decreased (medium 2 ; Table 2). $P$. septica colonies were $c .1 .5 \mathrm{~mm}$. in diameter and of normal appearance.

Neomycin $1.5 \mu \mathrm{g} . / \mathrm{ml}$. + Novobiocin $2 \mu \mathrm{g} . / \mathrm{ml}$. in medium 5 (Table 2), suppressed the growth of Pasteurella septica and $\boldsymbol{P}$. pseudotuberculosis, but allowed normal growth of $\boldsymbol{P}$. haemolytica (with the exception of one strain, C. 1675). Six of the 13 strains of $P$. pestis were partially inhibited. The addition of Erythrocin $5 \mu \mathrm{g} . / \mathrm{ml}$. to medium 5 (Table 2) improved the growth of $\boldsymbol{P}$. pseudotuberculosis, but inhibited $\boldsymbol{P}$. haemolytica (medium 6; Table 2).

\section{Tests with faecal and other suspensions}

Media 1 to 7 (Table 2) were tested with suspensions of faeces, soil and straw, artificially infected with Pasteurella pestis 37, P. septica 9592, P. pseudotuberculosis 8315 and $P$. haemolytica $B$ 1696. Medium 1 produced growth of c. 100 colonies of contaminant organisms/plate from faecal suspensions which produced confluent growth on basal nutrient agar. The colonies encountered on this medium were mainly of Alcaligenes spp. and were readily differentiated from pasteurella colonies. $\boldsymbol{P}$. pestis and $\boldsymbol{P}$. pseudotuberculosis were often isolated on medium 1 in pure culture from the soil and straw suspensions.

Pasteurella septica was readily isolated on media 2 and 3. Contaminant organisms growing on these media were mainly Streptococcus faecalis and 
Micrococcus spp. These organisms were further restricted by increasing the concentration of Tyrothricin in the media but the recoveries of $\boldsymbol{P}$. septica were then low. The other pasteurellas tested on media 2 and 3 did not grow from the artificially infected suspensions.

Pasteurella haemolytica was detected only on medium 5. Contaminant organisms growing on this medium were mainly Gram-positive bacteria and were readily differentiated from the pasteurella. $P$. pestis was also detected on medium 5 but in smaller numbers than on medium 1 .

The number of pasteurella colonies growing on all media from the faecal suspensions was usually about $50 \%$ of that expected from the size of inoculum,

Table 2. Growth of pasteurellas on basal nutrient agar containing $5 \%$ PSB with mixtures of selective agents added 
Table 2. (cont.)

\begin{tabular}{|c|c|c|c|c|c|c|c|c|}
\hline & \multicolumn{7}{|c|}{ Medium no. } \\
\hline & & 1 & 2 & $\mathbf{3}$ & 4 & 5 & 6 & 7 \\
\hline & & \multicolumn{7}{|c|}{ Selective agents added $(\mu \mathrm{g} . / \mathrm{ml})}$. \\
\hline & & $\begin{array}{r}\text { NOVO } 10 \\
\text { TELL } 5 \\
\text { ERYTH } 5\end{array}$ & $\begin{array}{c}\text { NEO 2.5 } \\
\text { TELL 2.5 } \\
\text { TYRO } 10\end{array}$ & $\begin{array}{l}\text { NEO 2.5 } \\
\text { TYRO } 10\end{array}$ & $\begin{array}{l}\text { NEO 2.5 } \\
\text { NOVO } 5 \\
\end{array}$ & $\begin{array}{l}\text { NEO 1.5 } \\
\text { NOVO } 2\end{array}$ & $\begin{array}{c}\text { NEO 1.5 } \\
\text { NOVO } 2 \\
\text { ERYTH } 5\end{array}$ & $\begin{array}{l}\text { NEO 1.5 } \\
\text { NOVO } 2 \\
\text { TYRO } 10\end{array}$ \\
\hline \multicolumn{9}{|c|}{ agar } \\
\hline \multicolumn{9}{|l|}{ P. septica } \\
\hline 9584 & TMA & - & sl. & + & - & - & - & - \\
\hline 9592 & & - & + & + & - & - & - & - \\
\hline 1876 & & - & tr. & tr. & - & - & - & - \\
\hline 9581 & & - & sl. & + & - & - & - & - \\
\hline 8141 & & - & + & + & - & - & - & - \\
\hline 8577 & & - & + & + & - & - & - & - \\
\hline 9586 & & - & tr. & tr. & - & - & - & - \\
\hline $5868 / 0$ & & - & + & + & - & - & - & - \\
\hline 9674 & & - & + & + & - & - & - & - \\
\hline $1140 / 0$ & & - & sl. & + & - & - & - & - \\
\hline 7460 & & - & + & + & - & - & - & - \\
\hline P 8 & & - & + & + & - & - & - & - \\
\hline 8195 & & - & + & + & - & - & - & - \\
\hline 4881 & & - & + & + & - & - & - & - \\
\hline 8283 & & - & + & + & - & - & - & - \\
\hline 1281 & & - & + & + & - & - & - & - \\
\hline $\mathbf{P} 7$ & & - & + & + & - & - & - & - \\
\hline \multicolumn{9}{|c|}{ P. haemolylica } \\
\hline A 1146 & $\mathbf{T A}$ & - & - & sl. & tr. & + & - & tr. \\
\hline В 1696 & & - & - & + & + & + & - & + \\
\hline C 1576 & & - & - & sl. & sl. & sl. & - & s1. \\
\hline C $1576 / \mathrm{r}$ & & - & - & + & + & + & - & + \\
\hline P 109 & & - & - & tr. & tr. & + & sl. & + \\
\hline P 110 & & - & - & sl. & + & + & - & tr. \\
\hline
\end{tabular}

* $+=100 \%$ of control count; tr. $=50 \%-80 \% ;$ sl. $=10 \%-50 \% ;-=$ no growth; NOVO=Novobiocin; TELL = potassium tellurite; ERYTH = Erythrocin; NEO = Neomycin; TYRO=Tyrothricin.

but on some occasions was only $5 \%$ of the expected count. High recoveries, of the order of $80 \%$, were constantly found from the soil and straw suspensions. It was necessary to include Actidione $100 \mu \mathrm{g} . / \mathrm{ml}$. or Mycostatin $200 \mathrm{units} / \mathrm{ml}$. in the selective media for inhibition of the majority of moulds encountered from the suspensions. The growth of pasteurellas was not affected by either addition.

\section{CONCLUSIONS}

The selective substances used in the formulation of these media were the most valuable found by screening tests on more than 100 substances. It was not possible to devise one medium that would grow all Pasteurella spp. and maintain simultaneously a high degree of selectivity since the pasteurellas differed in sensitivity to most of the substances tested. The media finally adopted 
represent a compromise between inhibition of the maximum number of contaminant organisms and the quantitative growth of the maximum number of pasteurella strains. This balance could be adapted to suit particular circumstances and for the detection of certain strains.

It should be noted that the results described are from examination of suspensions artificially infected with pasteurellas. Medium 1 has been used successfully, however, for the detection of Pasteurella pseudotuberculosis from faeces during a survey of over 400 'normal' guinea-pigs (Mr R. Cook, private communication). Each medium described has been used by the author for the separation of pasteurellas from contaminated cultures and for the isolation of these organisms from infected animals.

The three media which have been of the greatest use consist of TMA (for growth of Pasteurellas septica and $\boldsymbol{P}$. pseudotuberculosis) or TA (for $\boldsymbol{P}$. pestis and $\boldsymbol{P}$. haemolytica) containing $5 \%(\mathrm{v} / \mathrm{v})$ peptic sheep's blood (PSB) with the following additions :

Medium 1. For Pasteurella pestis and P. pseudotuberculosis. Novobiocin $10 \mu \mathrm{g} . / \mathrm{ml}$. + potassium tellurite $5 \mu \mathrm{g} . / \mathrm{ml}$. + Erythrocin $5 \mu \mathrm{g} . / \mathrm{ml}$. + Actidione $100 \mu \mathrm{g} . / \mathrm{ml}$. P. pseudotuberculosis also grew on this medium when PSB was omitted.

Medium 2. For Pasteurella septica. Neomycin $2.5 \mu \mathrm{g} . / \mathrm{ml} .+$ potassium tellurite $2.5 \mu \mathrm{g} . / \mathrm{ml}$. + Tyrothricin $10 \mu \mathrm{g} . / \mathrm{ml}$. + Actidione $100 \mu \mathrm{g} . / \mathrm{ml}$.

Medium 5. For Pasteurella haemolytica. Neomycin $1.5 \mu \mathrm{g} . / \mathrm{ml}$. + Novobiocin $2 \mu \mathrm{g} . / \mathrm{ml}$. + Actidione $100 \mu \mathrm{g} . / \mathrm{ml}$.

TMA was prepared by the method of Douglas, described by Fildes \& McIntosh (1931), using Kobé no. 1 agar powder (Stafford Allen and Sons Ltd.). TA was prepared from Difco Bacto tryptose solidified with the agar powder noted above. The sources of the antibiotics used were as follows: Novobiocin from Glaxo Laboratories Ltd., England ('Biotexin' brand of Novobiocin sodium); Neomycin from Upjohn of England Ltd. ('Mycifradin' Neomycin sulphate); Erythrocin from Abbott Laboratories Ltd., London; Tyrothricin from Parke, Davis and Co. Ltd., London; Actidione from The Upjohn Company, Michigan, U.S.A.; Mycostatin from E. R. Squibb and Sons, New York.

I am grateful to Dr D. W. Henderson and Dr H. M. Darlow for their interest and encouragement and to Mr C. M. R. Pitman for technical assistance.

\section{REFERENCES}

Drennan, J. G. \& Teague, O. (1917). A selective medium for the isolation of $B$. pestis from contaminated lesions. J. med. Res. 36, 519.

Frndes, P. (1920). A new medium for the growth of B. influenzae. Brit.J. exp. Path. $1,129$.

Findes, P. \& McIntosh, J. (1931). A System of Bacteriology in Relation to Medicine, 9, 59. London: H.M.S. Office.

Herbert, D. (1949). Studies on the nutrition of Pasteurella pestis, and factors affecting the growth of isolated cells on an agar surface. Brit. J. exp. Path. 30, 509. 
Meyer, K. F. \& Batchelder, A. P. (1926). Selective media in the diagnosis of rodent plague. J. infect. Dis. 39, 370.

Miles, A. A. \& Misra, S. S. (1938). The estimation of the bactericidal power of the blood. J. Hyg., Camb. 38, 732.

Thas, E. \& Chen, T. H. (1955). Two simple tests for the differentiation of plague and pseudotuberculosis bacilli. J. Bact. 69, 103.

(Received 27 March 1958) 